\title{
MOTION EVALUATION OF A WHEELCHAIR PROTOTYPE FOR DISABLED PEOPLE
}

\author{
GEONEA Ionut Daniel \\ Ph.D. Eng/ Assistant professor, Faculty of Mechanics / Department of Applied Mechanics, University of Craiova, \\ Craiova, Romania, igeonea@yahoo.com \\ DUMITRU Nicolae \\ Ph.D. Eng/Professor, Faculty of Mechanics / Department of Applied Mechanics, University of Craiova, \\ Craiova, Romania, nicolae_dtru@yahoo.com \\ MARGINE Alexandru \\ Ph.D. Eng/Professor, Faculty of Mechanics / Department of Applied Mechanics, University of Craiova, \\ Craiova, Romania, fam_margine@yahoo.com
}

\begin{abstract}
In this paper is presented the design solution and experimental prototype of a wheelchair for disabled people. Design solution proposed to be implemented uses two reduction gears motors and a mechanical transmission with chains. It's developed a motion controller based on a PWM technology, which allows the user to control the wheelchair motion. The wheelchair has the ability of forward - backward motion and steering. The design solution is developed in Solid Works, and it's implemented to a wheelchair prototype model. Wheelchair design and motion makes him suitable especially for indoor use. It is made a study of the wheelchair kinematics, first using a kinematic simulation in Adams. Are presented the wheelchair motion trajectory and kinematics parameters. The experimental prototype is tested with a motion analysis system based on ultra high speed video cameras recording. The obtained results from simulation and experimentally tests, demonstrate the efficiency of wheelchair proposed solution.
\end{abstract}

Key words: Wheelchair, kinematics, prototype, motion study.

\section{Introduction}

To assist mobility of disabled persons, several electrical powered wheelchairs are available on the market $[1,2,3,4,5,6,7,8]$. In the last 40 years, there have been revolutionary advances in power wheelchairs. These unique wheelchair systems, designed for the physically immobile patient, have become extremely diversified, allowing the user to achieve different positions, including tilt, recline, and more recently, passive standing [9].

The propulsion system of powered wheelchairs typically consists of a pair of motors, one for each drive wheel, and a drive train consisting of gears, belts and other mechanical elements that couples the motor's shaft to the drive wheel shaft. Speed and torque generated by each motor is controlled by modulating the pulse width. Solid state relays are generally used to switch supply voltage polarity to change the running direction of PM (permanent magnet) motors [9, 17]. The wheelchair's control module converts positional information from the joystick into power signals to the motors. Control modules are microprocessor based and have many adjustable parameters. Many control modules utilize feedback to sense whether the motor is responding properly to the joystick position. Such control systems adjust motor torque so as to maintain near constant speed while the load varies in response to changes in the terrain (incline, bumps) and surface (linoleum, carpeting, concrete, grass, sand) [5, 17].

Proposed solution uses an indirect drive transfer system, the motor is coupled to the drive wheel shaft through a system of gear train and flexible machine element (chains). The gear train and chain serve to reduce the motor speed while proportionately increasing motor torque [17]. Incorporating a transmission mechanism into the drive train would allow the PM motor to run efficiently for all speeds and torques and extend the serviceable lifetime of PM motor [17]. 


\section{Proposed design solution of wheelchair prototype}

Proposed solution of the wheelchair is designed in Solid Works, as shown in Fig. 1. Based on wheelchair dynamics are established the necessary torque and angular speed of propulsion motors upon are selected suitable motors and achieved the synthesis of transmission chain ratio to wheels. The wheelchair drive system uses two servomotors from Pololu, with reduction gears [18], with a duty torque by $12 \mathrm{Nm}$, at $30 \mathrm{rpm}$. The motion transmission to wheels is made with chain transmissions. Chain transmission multiplies two times the motor torque, and reduces the angular velocity. The obtained 3D virtual prototype is important because it will be used to simulate in Adams the wheelchair motion trajectory and study of motion dynamics. The experimental model of the wheelchair, assembled at Faculty of Mechanics, Craiova, is presented in Fig. 2.
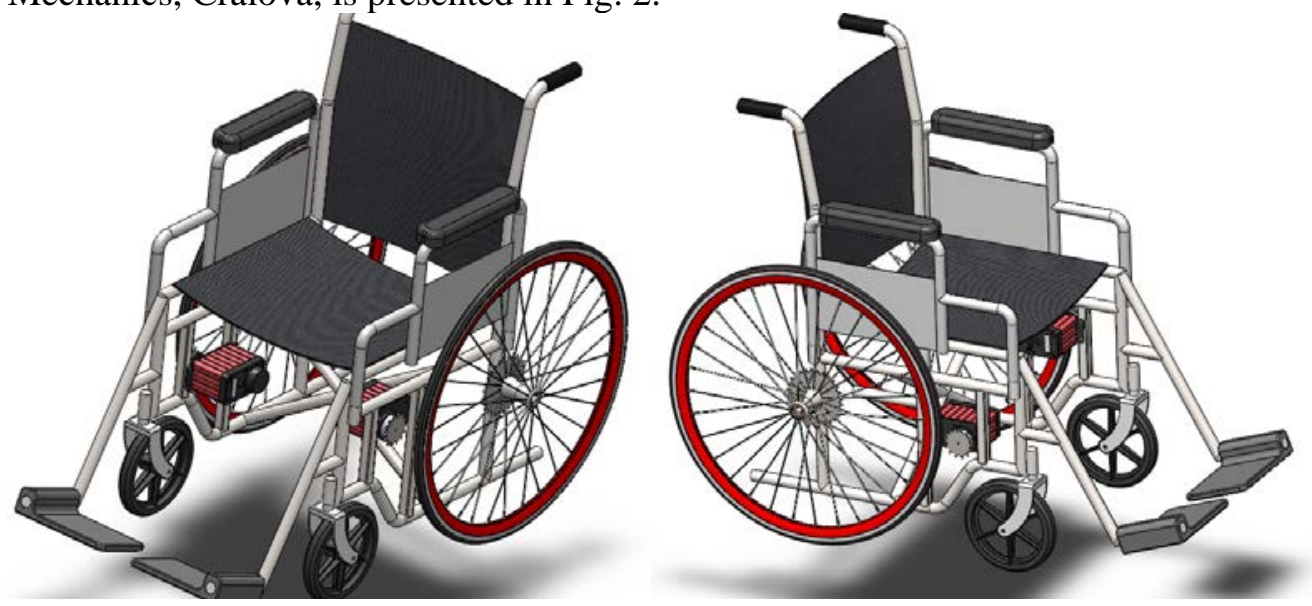

Figure 1: Wheelchair prototype designed in Solid Works.
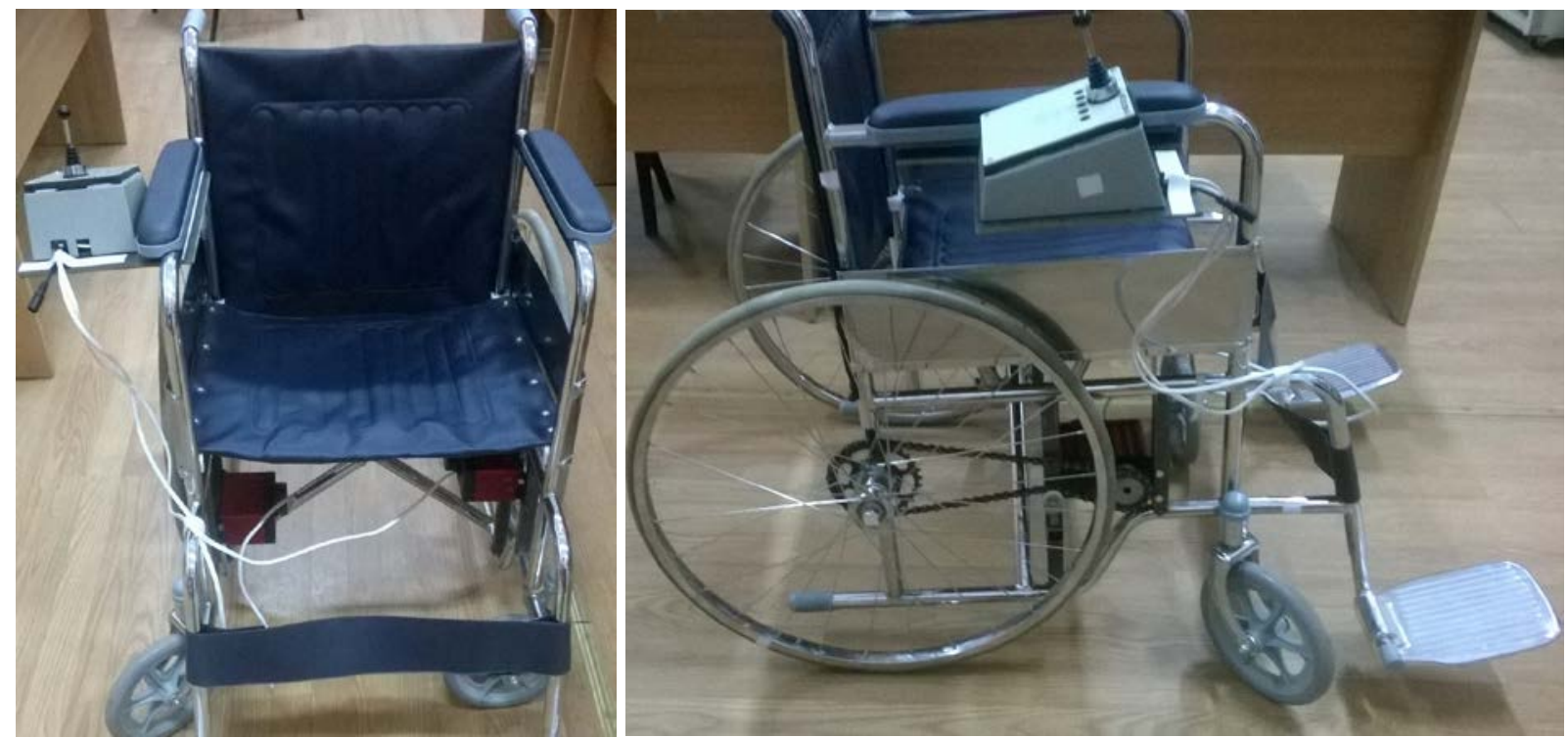

Figure 2: Wheelchair experimental prototype.

Mechanical design solution with chain transmissions (Fig. 3) is innovative from aspect of wheelchair folding for easy transportation. As is presented in Fig. 3 the motorized wheelchair keeps the folding capability. This is very useful in the situation when the person with disabilities is going to another location (a visit for example) and needs to move the wheelchair with a transportation vehicle. This can be done with a family vehicle. 

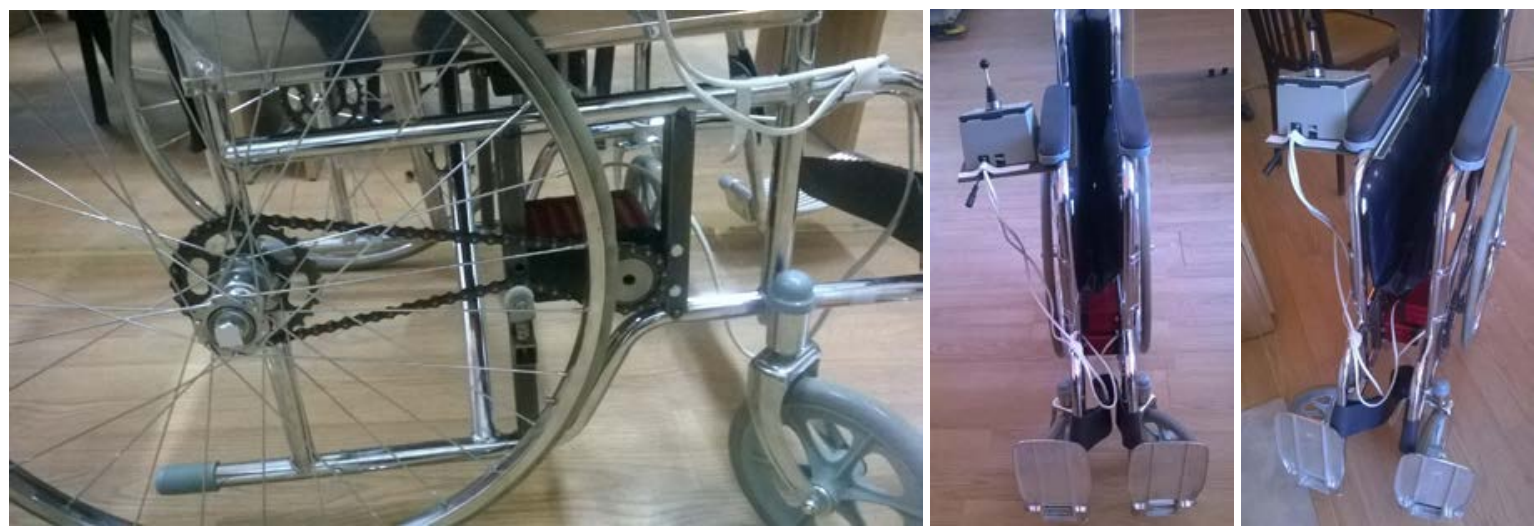

Figure 3: Details of chain transmission and wheelchair in folded position.

\section{Development of motion controller of the wheelchair}

Controller implemented is based on a L298N Dual H-Bridge Motor Controller module [20, 21]. $\mathrm{H}$-Bridge's are typically used in controlling motors speed and direction. An H-Bridge is a circuit that can drive a current in either polarity and be controlled by Pulse Width Modulation (PWM). Pulse Width Modulation is a means in controlling the duration of an electronic pulse. The microcontroller is based on Arduino Mega 2560 board. The Arduino Mega 2560 is a microcontroller board based on the ATmega2560.

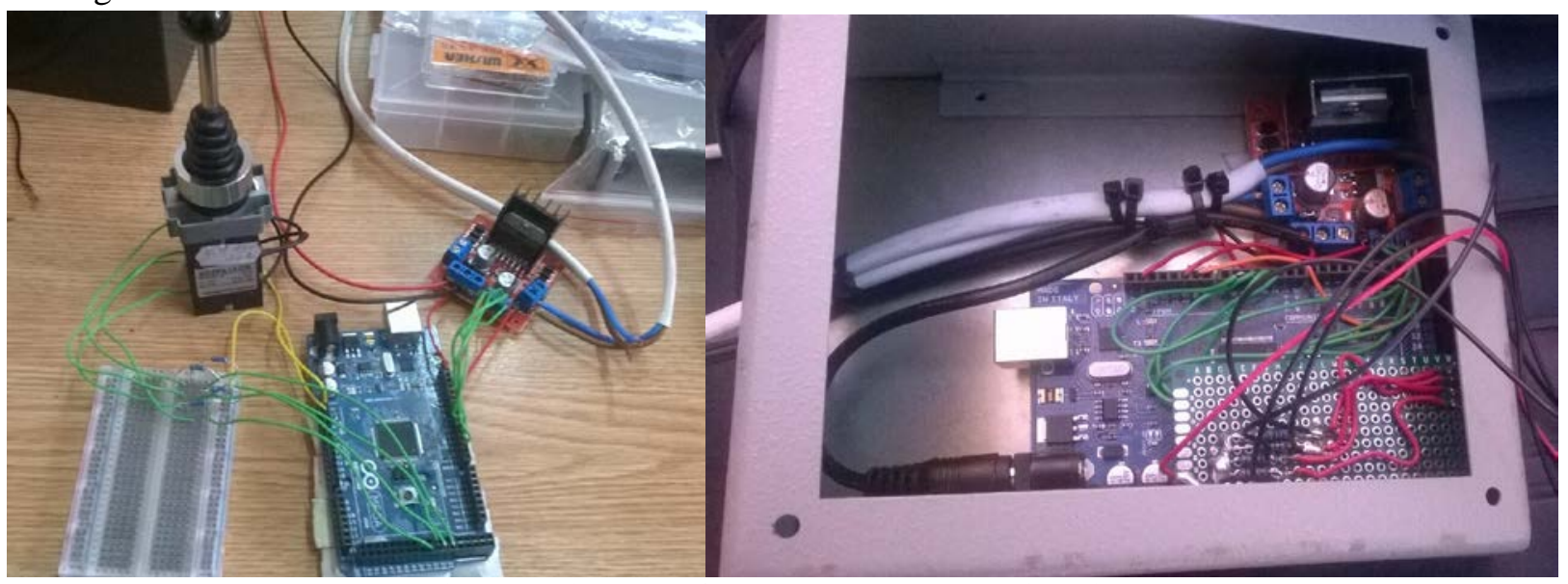

Figure 4: Aspects of PWM controller and joystick.

The program is written using the Arduino software. The Arduino's programming language makes PWM easy to use. It is used the function analogWrite(pin, dutyCycle), where dutyCycle is a value from 0 to 255 , and pin is one of the PWM pins $(3,5,6,9,10$, or 11$)$. The analogWrite function provides a simple interface to the hardware PWM, but doesn't provide any control over frequency [22]. Fragments of writhed and uploaded program, is shown in Fig. 5. 


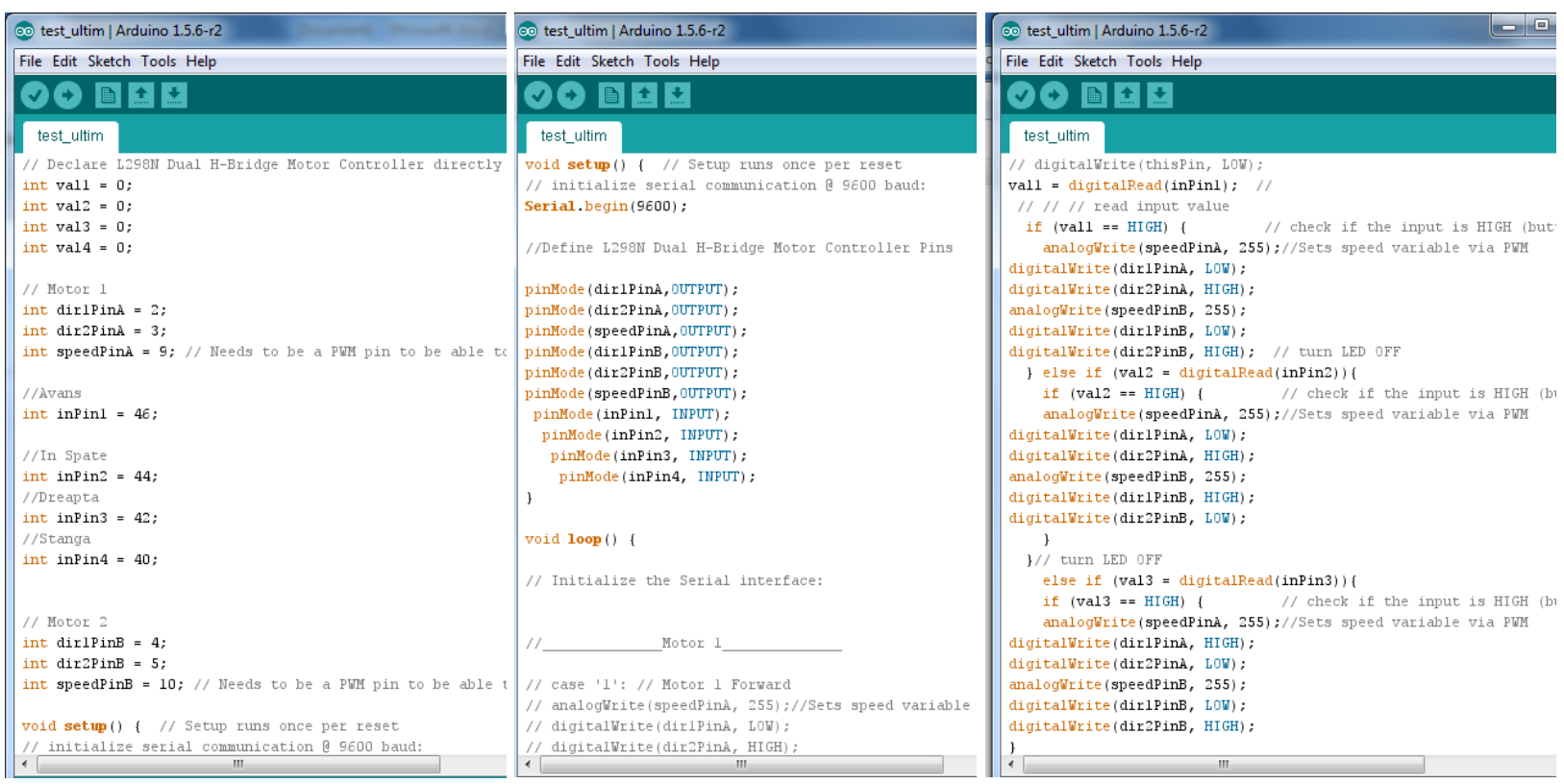

Figure 5: Details of program developed in Arduino language.

\section{Motion analysis of the wheelchair prototype}

The motion analysis of the wheelchair is studied in Adams software, in first phase. For that purpose the CAD model of the wheelchair is imported into Adams software database. Trough a suitable Adams developed algorithm is analyzed the wheelchair motion trajectory and motion parameters. To obtain a proper model in Adams, first are defined the material type of elements, upon the software calculates the inertia properties. Are defined the rotation joints of the wheels and also wheels -ground contact parameters. The front wheels are self directionally (caster wheels), and they are mounted on the wheelchair structure with axial-radial bearings. The kinematic model of the wheelchair constructed in Adams is presented in Fig. 6. It is used Adams Machinery, to define the sprocket set of the chain system and chain sprocket actuation input. Aspect of chain system modelled in Adams is shown in Fig. 6.

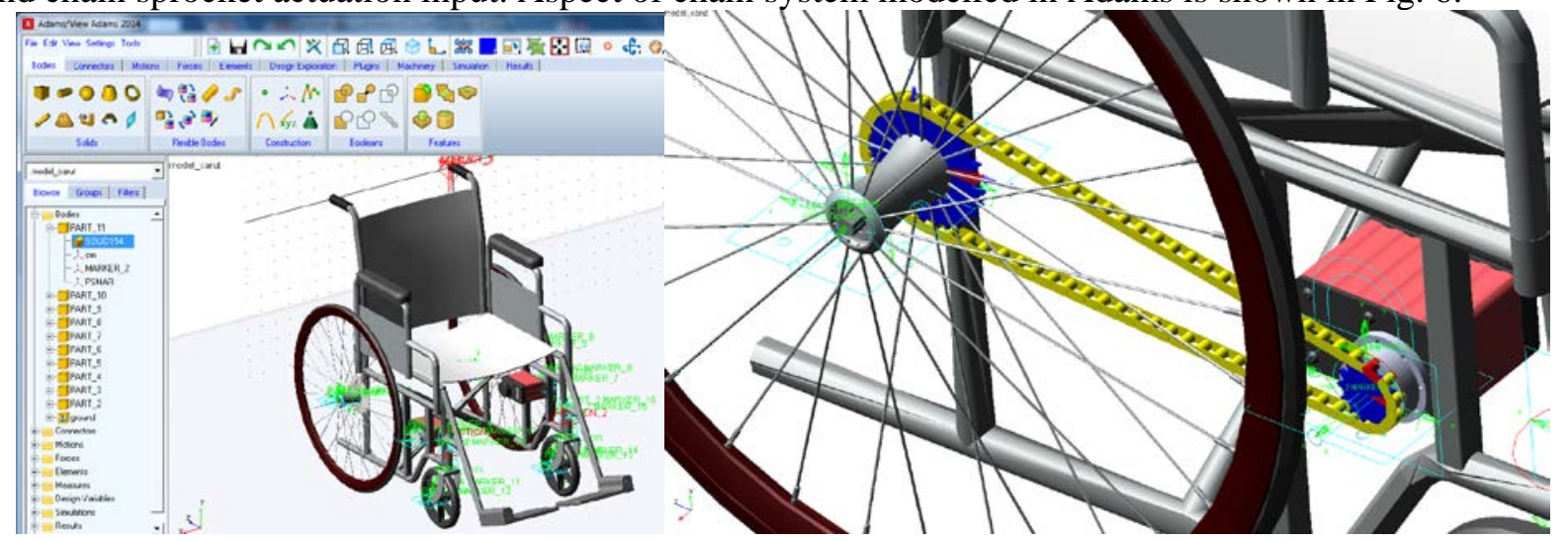

Figure 6: Kinematic model and aspect of chain system in Adams software.

It is solved the model in Adams, resulting robotic wheelchair motion trajectory, in first case for a straight line displacement, when both motors run with same angular velocity. For this simulation the both motors runs with $19 \mathrm{rot} / \mathrm{min}$ (but in opposite rotation directions), the wheelchair motion trajectory is shown in Fig. 7, a, and maximum motors torque is by $2,5 \mathrm{Nm}$. The wheelchair propulsion speed is constant and is by $400 \mathrm{~mm} / \mathrm{s}$. For the second simulation case, the right motor runs with $9,5 \mathrm{rot} / \mathrm{min}$ and left motor runs with $19 \mathrm{rot} / \mathrm{min}$, the wheelchair obtained trajectory is shown in Fig. 7, b. The wheelchair motors torque, measured in Adams simulation is by $10 \mathrm{Nm}$, for right motor, and by $7 \mathrm{Nm}$ for left motor. Is observed that is needed a greater torque for right wheel, because it's spins with a lower angular speed. 


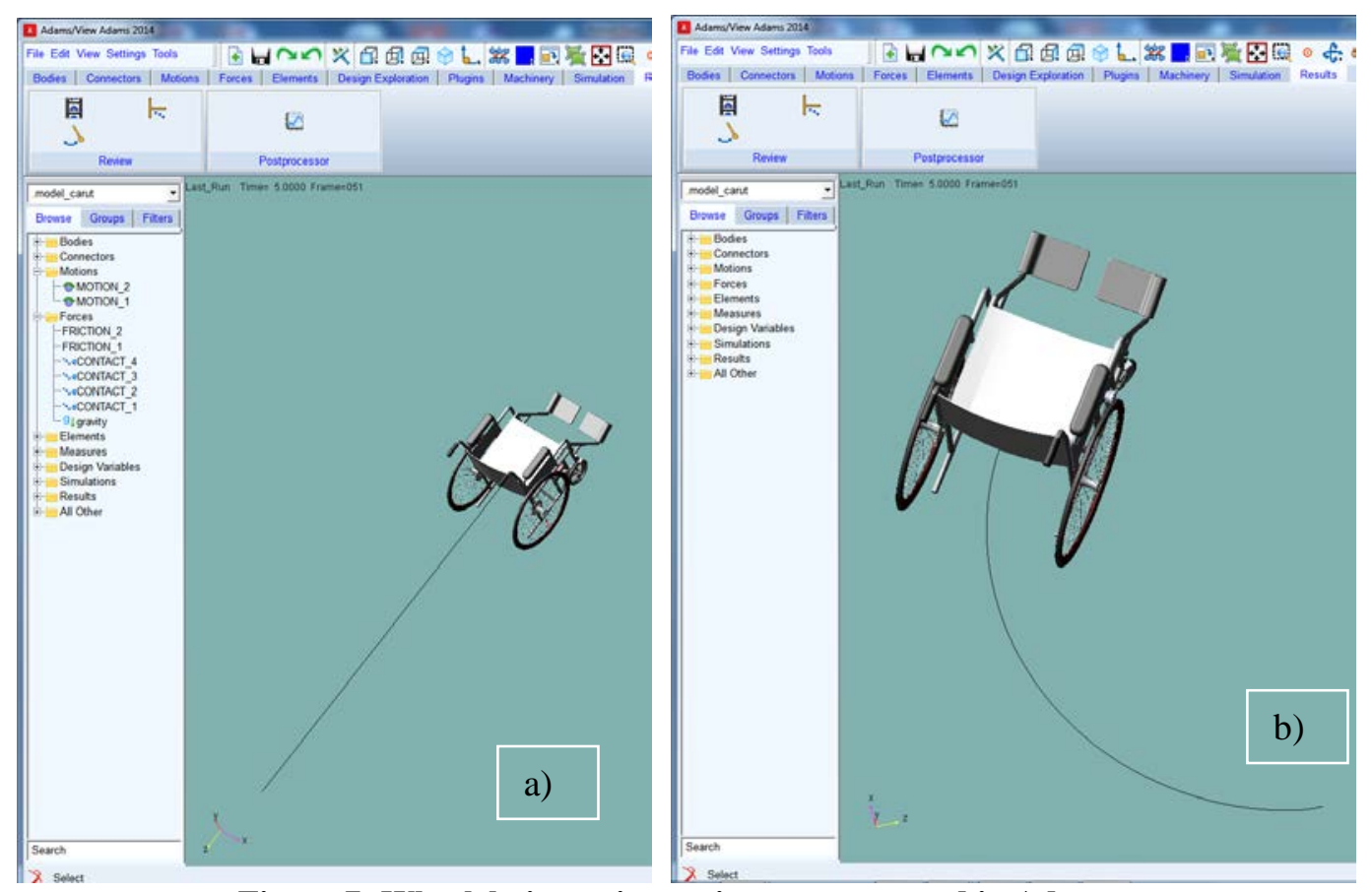

Figure 7: Wheelchair motion trajectory computed in Adams.

Computed torque variation in Adams simulation are presented in Fig. 8, for right wheel and left wheel motor.
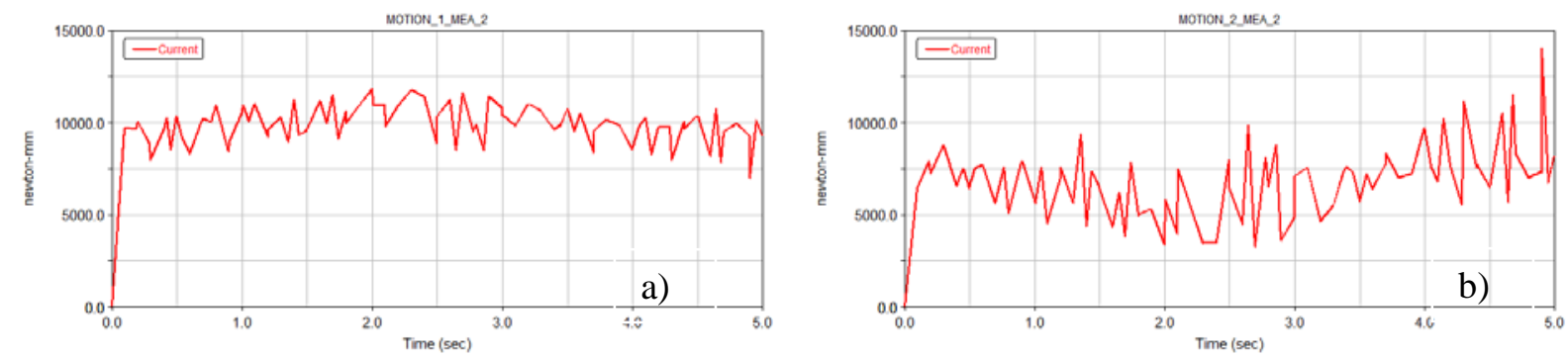

Figure 8: Adams computed torque. a) -right wheel, b)- left wheel.

For wheelchair experimental motion evaluation it is used Contemplas motion analysis equipment, based on ultra speed cameras. Reflective markers have been attached to the wheelchair frame and wheel. The marker motion is captured and processed with TempoloMotion software in order to establish wheelchair wheels rotation and displacement variation in time. Positioning of reflective marker and motion tracking results are indicated in Fig. 9.

The notations used are the following: 1, 2 - frame attached reflective markers; 3- wheel centre attached marker; 4 - wheel circumference attached marker.

With Contemplas motion analysis equipment, the wheelchair is analyzed during a straight line displacement. Obtained results for markers trajectories are presented in the Fig. 9. Markers tracking for wheel angular variations measure are presented in Fig.10. The graphic of wheel angular displacement variation is presented in Fig. 11.

It is observed that the wheel circumference marker describes a cycloid curve, and markers attached to the frame are describing a straight line. Motion tracking allow establishing the wheel angular position, and also angular velocity. 


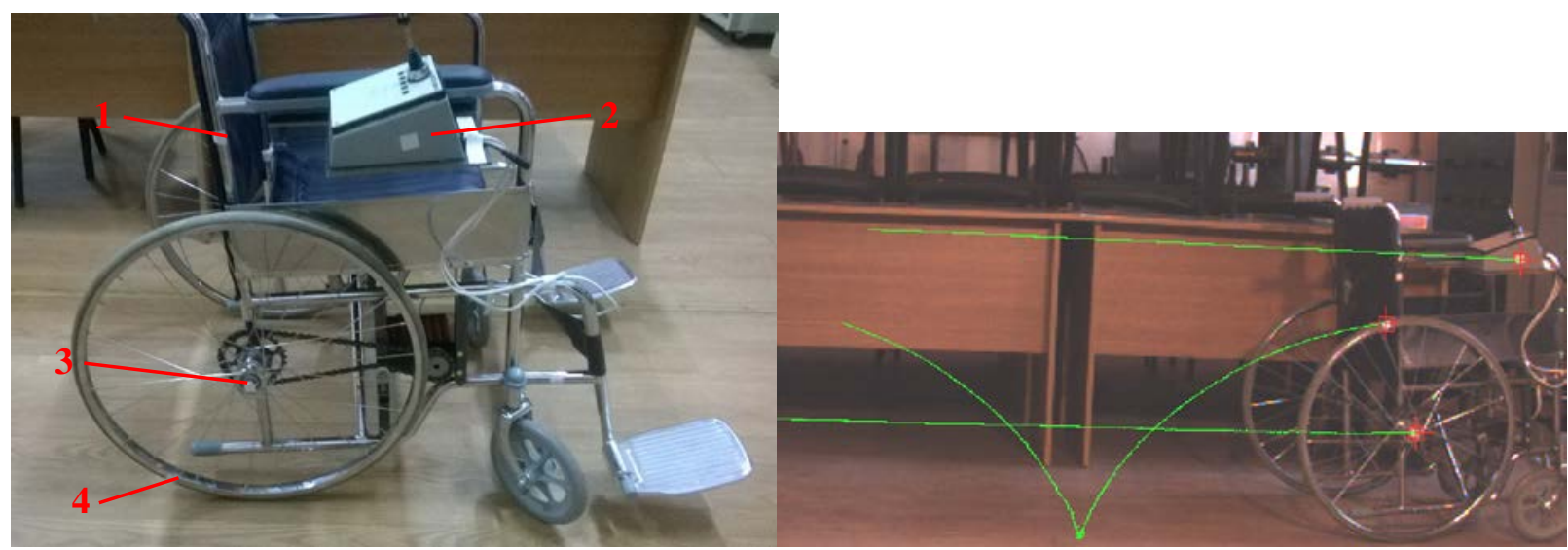

Figure 9: Positioning of reflective markers on the wheelchair and markers computed trajectories.

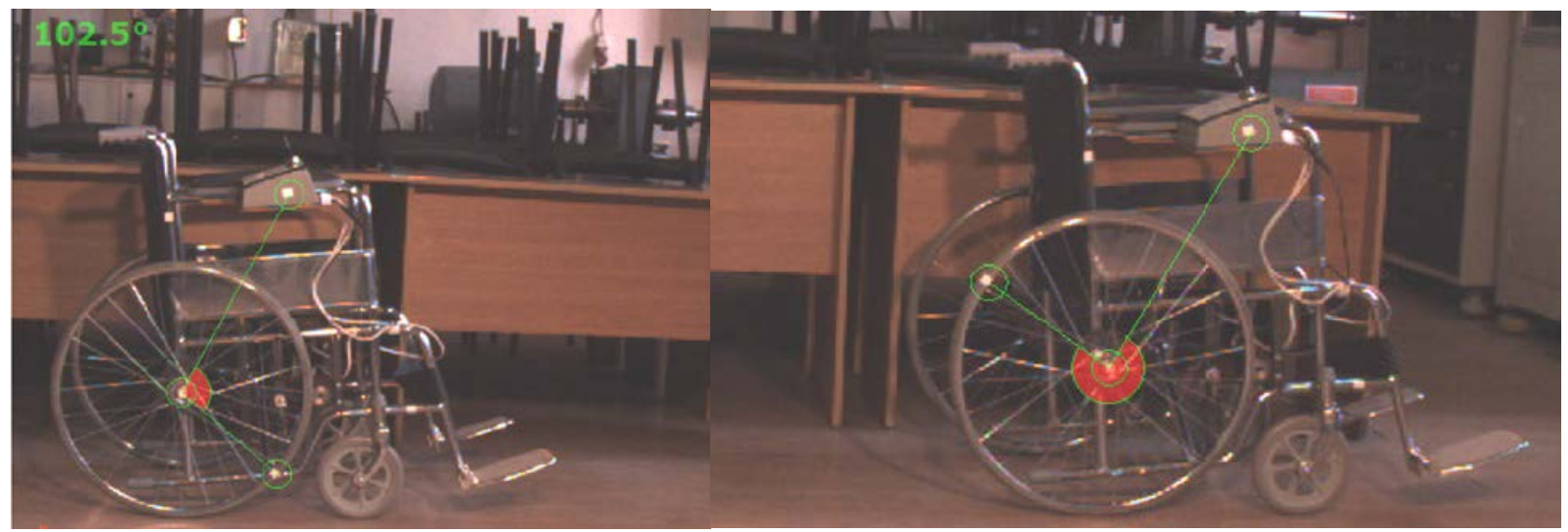

Figure 10: Marker tracking for measure wheel angular motion.

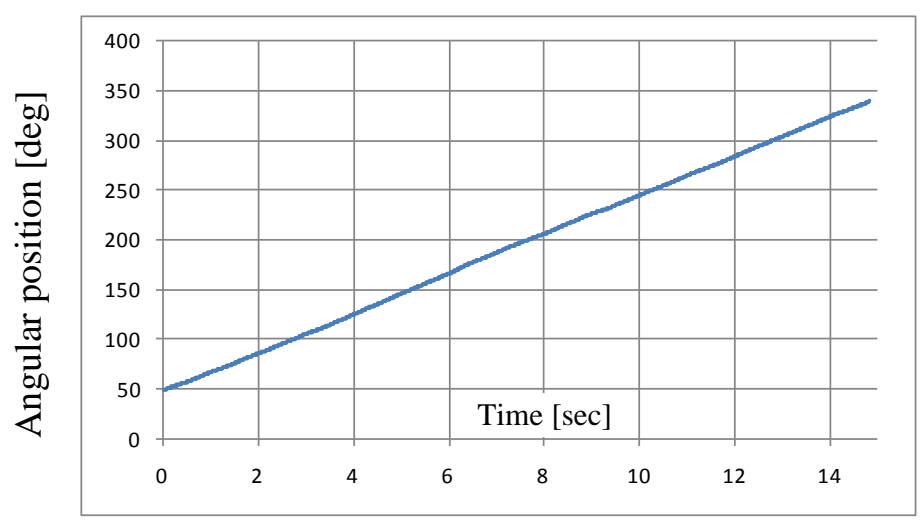

Figure 11: Time variation of wheel angular position.

\section{Conclusions}

This paper proposes to develop a kinematic analysis model of a robotic wheelchair prototype, which will be used for further dynamic studies. In order to increase efficiency propulsion motors must run at a high angular speed. For that are implemented motors with reduction gears and chain drive trains, which convert high motor speed to lower speeds but with increased torque. The virtual model of the wheelchair is designed in Solid Works and upon this model is developed the experimental model. Proposed solution uses two motors, controlled by a joystick module, based on a PWM controller. Kinematic analysis reveals motion trajectories of wheelchair, kinematic parameters of the system: wheel angular displacement and speed, running speed. Further studies concerns the motion study for steering situation, and establish of dynamic parameters of the wheelchair: electric DC motors propulsion and steering torque. 
Acknowledgments: This work was supported by the strategic grant POSDRU/159/1.5/S/133255, Project ID 133255 (2014), co-financed by the European Social Fund within the Sectorial Operational Program Human Resources Development 2007-2013.

\section{References}

1. Gonzalez-Rodriguez Antonio, Mechanical Synthesis for Easy and Fast Operation in Climbing and Walking Robots, Climbing and Walking Robots, Intech Viena, 2010.

2. Gurpude R., Design, Synthesis \& Simulation Of Four Bar Mechanism For Guiding Wheel For Climbing, International Journal of Engineering Research and Applications, 2012.

3. Hassan Abdulkadir, Design and Fabrication of a Motorized Prototype Tricycle for the Disable Persons, IOSR Journal of Engineering, May 2012, Vol. 2(5), pp.1071-1074.

4. Kumar Vijay, Assistive Devices for People with Motor Disabilities, Wiley Encyclopedia of Electrical and Electronics Engineering. Assistive Devices for People With Motor Disabilities, 1997.

5. Modak G. S., Review Article: Evolution of a Stair-Climbing Power Wheelchair, IOSR Journal of Mechanical and Civil Engineering (IOSR-JMCE), pp. 36-41, 2009.

6. Pires G., Autonomous Wheelchair for Disabled People, Proc. IEEE Int. Symposium on Industrial Electronics (ISIE97), Guimarães, 797-801, 1997.

7. Rajasekar R., Design and fabrication of staircase climbing wheelchair, Int. J. Mech. Eng. \& Rob. Res., 2013.

8. Reswick JB., Automatic transmission for electric wheelchairs, J. Rehabil. Res. Dev., 1985.

9. R.F. Edlich, K.P. Nelson, M.L. Foley, R.M. Buschbacher, W.B. Long and E.K. Ma, Technological advances in powered wheelchairs, J. Long. Term. Eff. Med. Implants, vol. 14, pp.107-130, 2004. http://dl.begellhouse.com/journals/1bef42082d7a0fdf,06d27aa539906a9e,7b5a4f3a4794918e.html.

10. Salmin H., Design and Implementation of an Electric WheelChair to Economize it with Respect to Bangladesh, International Journal Of Multidisciplinary Sciences And Eng. 2014.

11. Shanu Sharma, User Centric Designed Mechanism For stairs-climbing Wheelchair, ${ }^{15}$ th National Conference on Machines and Mechanisms NaCoMM, 2011.

12. Sheng L.J., Wireless brain computer interface for electric wheelchairs with EEG and eye-blinking signals, International Journal of Innovative Computing, Information and Control, 2012.

13. Wellman, P., Design of a Wheelchair with Legs for People with Motor Disabilities, IEEE Transactions on Rehabilitative Eng. Vol. 3, pp.343-353, 1995.

14. Wolm P., Dynamic stability control of front wheel drive wheelchairs using solid state accelerometers and gyroscopes, PhD Thesis, University of Canterbury, 2009.

15. MSC Inc., MSC Adams 2013 reference manual.

16. Contemplas Software user manual.

17. http://www.wheelchairnet.org/WCN_WCU/Research/StakeholderDocs/PDFs/motors.pdf

18. https://www.pololu.com/product/1390/specs

19. http://paper.uscip.us/jvamc/jvamc.2014.1002.pdf

20. http://www.instructables.com/id/Arduino-Modules-L298N-Dual-H-Bridge-Motor-Controll/

21. http://www.mantech.co.za/datasheets/products/A000047.pdf

22. http://www.arduino.cc/en/Tutorial/SecretsOfArduinoPWM 